\title{
Supported Dense Ceramic Membranes for Oxygen Separation
}

\author{
Annual Report \\ Period Starting: June 25, 1998 \\ Period Ending: June 24, 1999
}

Timothy L. Ward

June 2000

DOE Award No.: DE-AC26-98FT40120--01

University of New Mexico

Department of Chemical and Nuclear Engineering

Albuquerque, NM 87131 


\section{DISCLAIMER}

This report was prepared as an account of work sponsored by an agency of the United States Government. Neither the United States Government nor any agency thereof, nor any of their employees, makes any warranty, express or implied, or assumes any legal liability or responsibility for the accuracy, completeness, or usefulness of any information, apparatus, product or process disclosed, or represents that its use would not infringe privately owned rights. Reference herein to any specific commercial product, process, or service by trade name, trademark, manufacturer, or otherwise does not necessarily constitute or imply its endorsement, recommendation, or favoring by the United states Government or any agency thereof. The views and opinions of authors expressed herein do not necessarily state or reflect those of the United States Government or any agency thereof. 


\begin{abstract}
This report describes results from the first contract year of a research project whose overall objective is to explore the fundamental and practical issues confronting the successful development of thick-film dense ceramic membrane technology for oxygen separation applications. Porous substrates (discs) were fabricated from commercially-purchased powder with compositions of $\mathrm{SrCo}_{0.8} \mathrm{Fe}_{0.2} \mathrm{O}_{\mathrm{y}}$ and $\mathrm{SrCo}_{0.5} \mathrm{FeO}_{\mathrm{x}}$. The sintering behavior of these powders was investigated, and appropriate standard preparation methodologies were determined to provide substrates possessing acceptable porosity and strength. For the fabrication of the dense membrane layer, the $\mathrm{SrCo}_{0.5} \mathrm{FeO}_{\mathrm{x}}$ composition was emphasized because it is more stable under reducing conditions that are typical of some important applications. The $\mathrm{SrCo}_{0.5} \mathrm{FeO}_{\mathrm{x}}$ powder to be used for thick film deposition was synthesized using aerosol pyrolysis. The effect of synthesis temperature and gas atmosphere on particle morphology and crystalline phase content were evaluated. Powder produced at $700{ }^{\circ} \mathrm{C}$ possessed $\mathrm{x}$-ray diffraction patterns indicating the Sr-Co-Fe-O perovskite phase. Typical average particle size of the aerosol-derived powder is approximately 0.2-0.3 $\mu \mathrm{m}$. Two alternate methods were evaluated for deposition of $\mathrm{SrCo}_{0.5} \mathrm{Fe}_{\mathrm{x}}$ thick films upon the porous substrates: direct deposition of a dilute slurry of the ultrafine aerosol powder onto the porous substrate, and doctor blading of a paste made from the aerosol powder and polypropylene glycol (PPG). Slurry deposition provided micron-thick layers, and required multiple deposition-sintering cycles to provide layers of the desired thickness for subsequent membrane densification. The doctor blade method provided membrane layers of at least 5 - 10 $\mu \mathrm{m}$ thickness in a single deposition. Sintering studies of the supported films has just begun. Results thus far show pronounced cracking and opening up of the membrane films with densification. Understanding the densification process and overcoming this problem is a major objective for future work.
\end{abstract}




\section{TABLE OF CONTENTS}

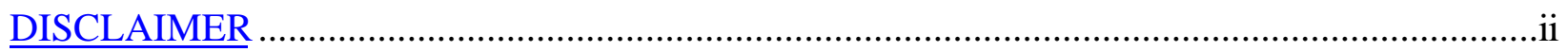

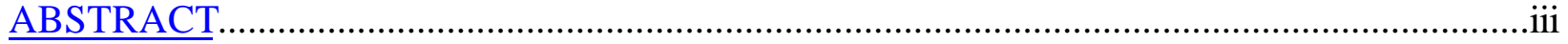

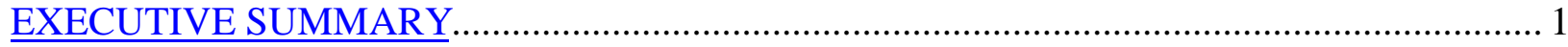

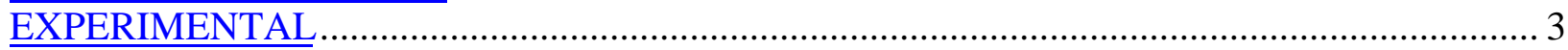

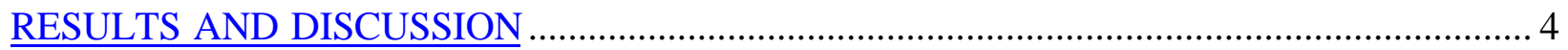

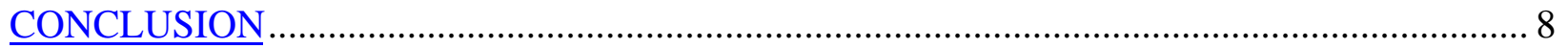

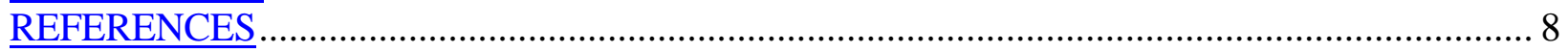




\section{EXECUTIVE SUMMARY}

The overall objective of this project is to explore important fundamental and practical issues confronting the successful development of thick-film dense ceramic membrane technology for oxygen separation. Ceramic mixed-conducting membranes separate oxygen with perfect selectivity via ionic oxygen transport through the oxygen vacancies in the crystalline material. ${ }^{1-8}$ The potential impact of such membranes for high-temperature applications such as partial oxidation reactors and oxidative reformers is well recognized. ${ }^{1-3}$

Specific tasks and objectives of the project include:

- explore strategies for the successful fabrication of defect-free thick-film Sr-Co-Fe-O (SCFO) membranes on porous supports, emphasizing deposition and subsequent densification of ultrafine powders produced by aerosol methods. ${ }^{9,10}$

- develop an improved understanding of particle deposition and infiltration into porous granular supports, and the relationship to sintering behavior, film adhesion, and stability.

- explore and demonstrate the use of a novel metal organic chemical vapor deposition technique to mend membrane defects.

The fabrication strategy in this project is to deposit thin or thick films of ultrafine powders produced by aerosol pyrolysis ${ }^{9,10}$ onto (or into) partially sintered porous supports, followed by co-sintering of the film and support, with the objective of densifying the film while retaining open porosity in the support (Fig. 1). The supports were made using commercially-produced $\mathrm{SrCo}_{0.5} \mathrm{FeO}_{\mathrm{x}}$ or $\mathrm{SrCo}_{0.8} \mathrm{Fe}_{0.2} \mathrm{O}_{\mathrm{y}}$ powder (Prax-Air). The same two compositions were investigated as possible membrane layers. The $\mathrm{SrCo}_{0.8} \mathrm{Fe}_{0.2} \mathrm{O}_{\mathrm{y}}$ composition has one of the highest reports oxygen permeabilities. ${ }^{5-7}$ However $\mathrm{SrCo}_{0.5} \mathrm{FeO}_{\mathrm{x}}$ is reported to be much more stable in reducing environments that are typical of important applications involving synthesis $\left(\mathrm{CO} / \mathrm{H}_{2}\right)^{3,8}$ For this reason, most of the work has centered on that composition.
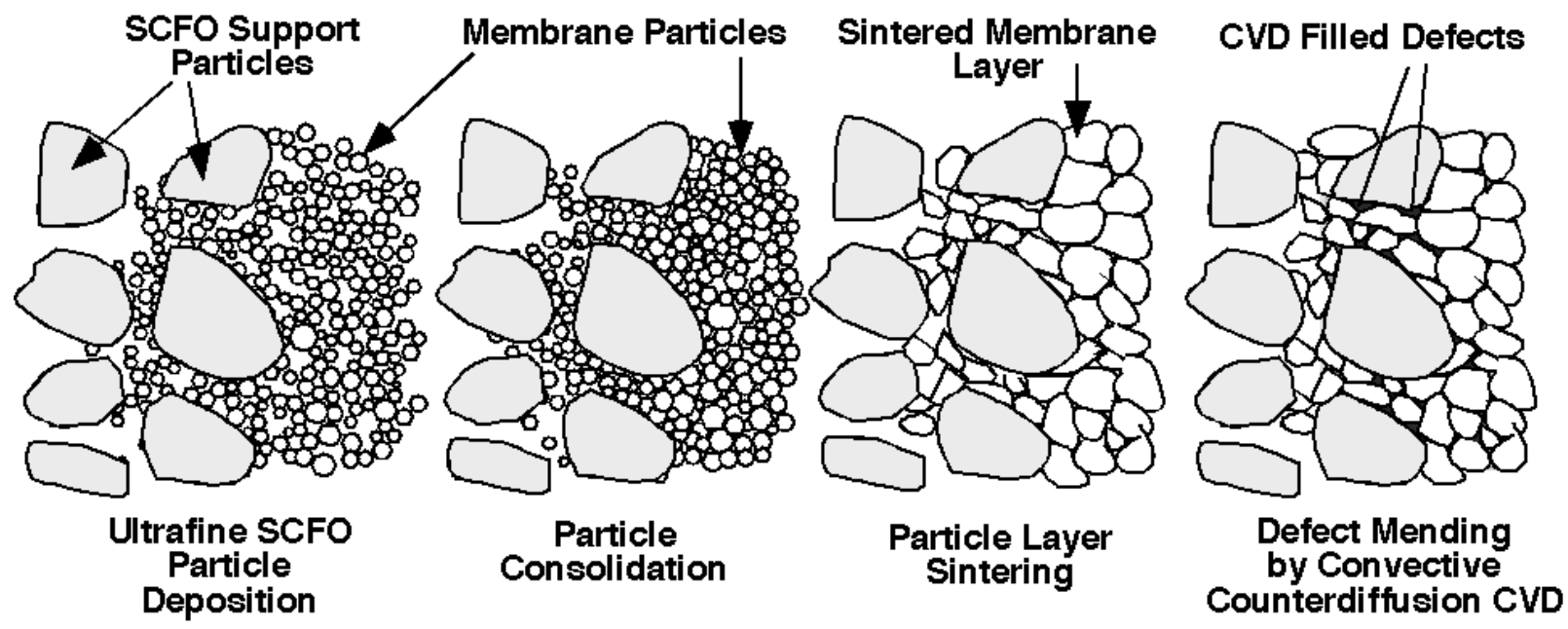

Fig. 1. Schematic of the strategy for fabricating and mending supported mixed-conducting membranes using fine aerosol-produced powders on porous supports. 
In the first project year, substantial progress was made on fabrication of the porous supports, and methods of thick film deposition were screened, leading to adoption of a doctor blading process for subsequent membrane deposition and sintering studies. The supports were made by uniaxial pressing of powder at $64 \mathrm{MPa}$, followed by sintering in a controlled environment. Sintering of the supports must be done so that the final strength of the support will withstand subsequent processing, while substantial open porosity is retained in the support. The $\mathrm{SrCo}_{0.8} \mathrm{Fe}_{0.2} \mathrm{O}_{\mathrm{y}}$ and $\mathrm{SrFeCo}_{0.5} \mathrm{O}_{\mathrm{x}}$ compositions were investigated as possible supports, and sintering in both air and $\mathrm{N}_{2}$ was investigated. The sintering rate, support microstructure, and crystalline phase content all were dependent on the composition and sintering atmosphere. Sintering in air leads to plateshaped grains which retain considerable open porosity until temperatures near melting are reached; whereas, sintering in $\mathrm{N}_{2}$ leads to more rapid densification with equiaxed grains. A standard support sintering treatment was adopted for subsequent membrane deposition experiments. That treatment involved sintering in air at $1050{ }^{\circ} \mathrm{C}$ (ramp rate $5^{\circ} \mathrm{C} / \mathrm{min}$ with $2 \mathrm{hr}$ soak) to give supports with typical thickness of $1.5 \mathrm{~mm}$, diameter $13.4 \mathrm{~mm}$, and $~ 50 \%$ porosity.

The submicron powders to be used for membrane layer deposition were fabricated using the aerosol pyrolysis technique. An aerosol was generated from a mixed nitrate solution containing the metals $\mathrm{Sr}, \mathrm{Co}$ and $\mathrm{Fe}$ in the desired ratio. The roughly micron-sized droplets were carried through a tube furnace where the nitrates decomposed to yield the crystalline oxide powder. Synthesis in both air and $\mathrm{N}_{2}$ was investigated. It was found that both atmospheres produced a powder whose elemental composition was very close to the desired (solution) composition, and that both powdesr consisted primarily of the perovskite phase. For the majority of powder synthesis experiments, air at $700{ }^{\circ} \mathrm{C}$ was chosen, yielding a nearly single-phase Sr-Co-Fe-O perovskite powder with mean particle size of roughly $0.3 \mu \mathrm{m}$.

Several methods were investigated for deposition of membrane layers using the submicron aerosol powder. Relatively dilute slurries (water or alcohol based) were deposited onto the porous substrates by a spin coating/slip casting process or by pressurized filtration. The spin coating method gave very thin layers requiring many layers of deposition, and the pressure filtration method was difficult to achieve uniform edge-to-edge coverage. A doctor blade technique using a paste made from the aerosol powder and $400 \mathrm{MW}$ polyethylene glycol (PEG) was also tried, and this technique was ultimately adopted as the standard method for membrane fabrication. Using the doctor blade method, single applications yielded layers of 5-10 $\mu \mathrm{m}$ thickness. The paste had a relatively low solid content ( $20-30 \mathrm{wt} \%$ powder $)$ in order to have desired consistency. Sintering studies on the supported thick films have just begun, and initial experiments reveal considerable cracking and opening up of the membrane film during film shrinkage. 


\section{EXPERIMENTAL}

The powder used for support fabrication $\left(\mathrm{SrCo}_{0.8} \mathrm{Fe}_{0.2} \mathrm{O}_{\mathrm{y}}\right.$ and $\left.\mathrm{SrCo}_{0.5} \mathrm{FeO}_{\mathrm{x}}\right)$ was commercially obtained from Prax Air (Woodinville, WA). After some investigation into optimal fabrication conditions, supports were fabricated by uniaxial pressing of powder in a $0.5 \mathrm{in}$. die at $64 \mathrm{MPa}$, followed by sintering in air at $1050{ }^{\circ} \mathrm{C}(2 \mathrm{hr}$ soak and $5 / \mathrm{min}$ ramp rate). Sintering was conducted in a muffle furnace for air sintering, and in a tube furnace with continuous $\mathrm{N}_{2}$ flow for $\mathrm{N}_{2}$ sintering. Powder used to fabricate the ceramic membrane layer was synthesized using aerosol pyrolysis. A TSI 3076 aerosol generator was used with air or $\mathrm{N}_{2}$ carrier/atomizing gas (35 psig, $1.5 \mathrm{slpm}$ ) to create an aerosol from an aqueous metal nitrate solution containing the metals in the desired ratio. The aerosol was carried through a three-zone Lindbergh furnace with $3 \mathrm{ft}$. heated length. The tube diameter $(15 \mathrm{~cm})$ provided a residence time of approximately 2.4 min. at $700{ }^{\circ} \mathrm{C}$, which was the temperature adopted for the majority of powder syntheses. The powder was collected on a $142 \mathrm{~mm}$ diameter filter (cellulose acetate, $0.45 \mu \mathrm{m}$ ) after leaving the tube furnace (Fig. 2).

\section{AEROSOL POWDER SYNTHESIS}

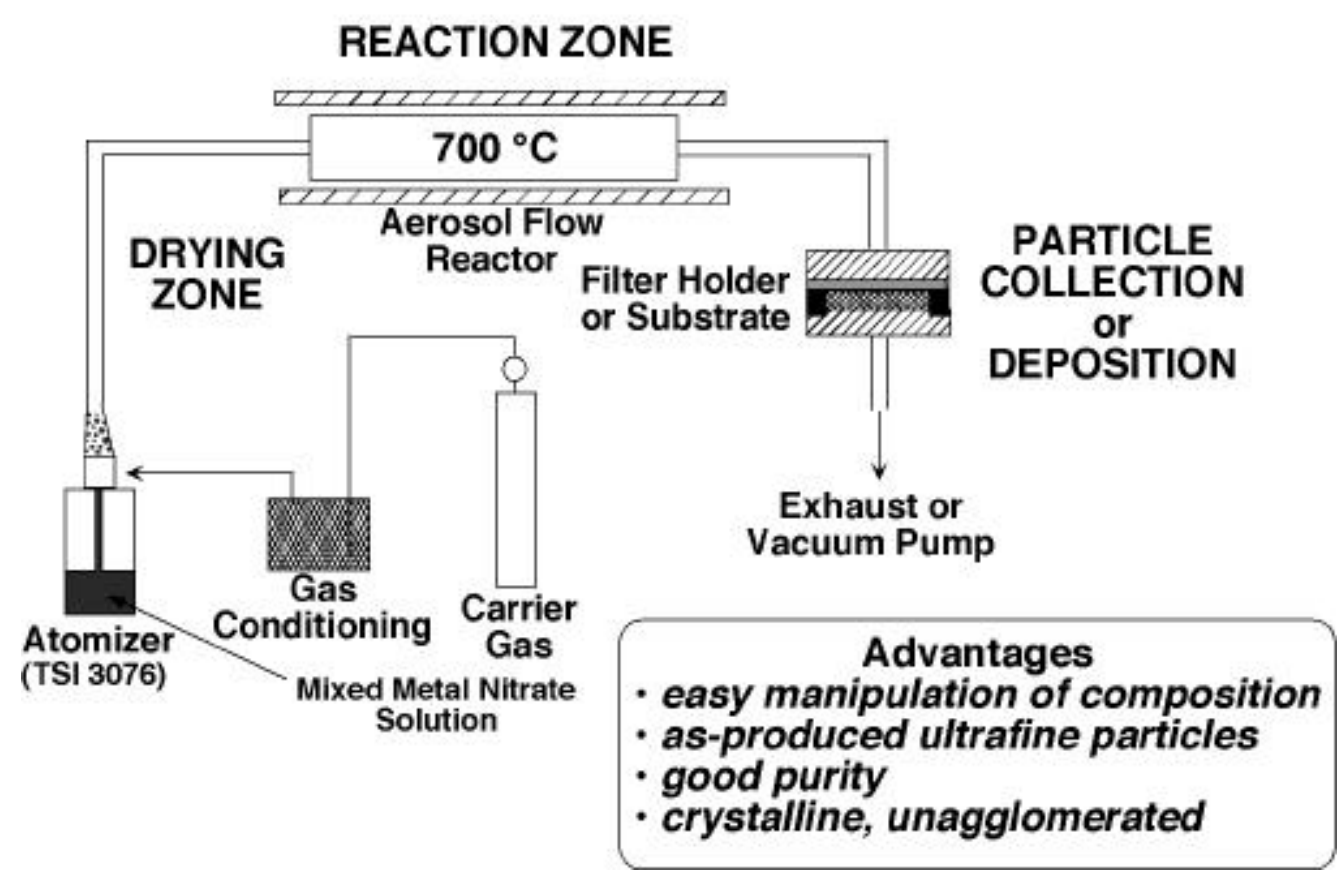

Fig 2. Aerosol pyrolysis process for producing submicron SCFO powder for membrane fabrication.

Membrane layers were deposited by several methods. Relatively dilute slurries (water or alcohol based) were deposited onto the porous substrates by spin coating and slip casting processes. For the slip-casting process, a dilute slurry was applied dropwise to the porous support. For the spin coating method, a thin layer of slurry was applied then spun using the spin coater (Headway), followed by reapplicatio. Both of these methods gave very thin layers requiring many layers of deposition. A doctor blade technique using a paste made from the powder and $400 \mathrm{MW}$ polyethylene glycol (PEG) was also tried, and this technique was ultimately adopted as the default method for membrane fabrication. The paste was made by dispersal of the powder into 
polyethylene glycol (PEG; MW=400) to provide a paste which was approximately $20 \mathrm{wt} \%$ solid. Alternative diluents are also being investigated. Characterization methods employed have included atomic absorption (AA), x-ray diffraction (XRD), and scanning electron microscopy (SEM).

\section{RESULTS AND DISCUSSION}

The compositions of commercially obtained powders for support fabrication were checked using AA. The powder that had a nominal composition $\mathrm{SrCo}_{0.5} \mathrm{FeO}_{\mathrm{x}}$, was found to be somewhat lower in $\mathrm{Sr}$ and richer in iron than expected, with a composition of $\mathrm{Sr}_{0.85} \mathrm{Co}_{0.5} \mathrm{Fe}_{1.07} \mathrm{O}_{\mathrm{x}}$. However this difference was not expected to cause major problems in the support, since chemical compatibility with the membrane layer would still be very good. The densification behavior of the powders was evaluated to allow fabrication of supports with sufficient strength while maintaining substantial open porosity. For sintering in air, densification begins to accelerate at around 900 ${ }^{\circ} \mathrm{C}$, and roughly $90 \%$ theoretical density is achieved at $1100{ }^{\circ} \mathrm{C}$ (Fig. 3). Sintering in $\mathrm{N}_{2}$ was also conducted, though the data as a function of temperature are not yet complete and are not shown in Fig. 3. However, sufficient experiments have been done to make it very apparent that sintering if more rapid in the $\mathrm{N}_{2}$ atmosphere. Furthermore, sintering in air led to a microstructure consisting of plate-shaped grains, whereas sintering in $\mathrm{N}_{2}$ provides more equiaxed particles (Fig. 4).

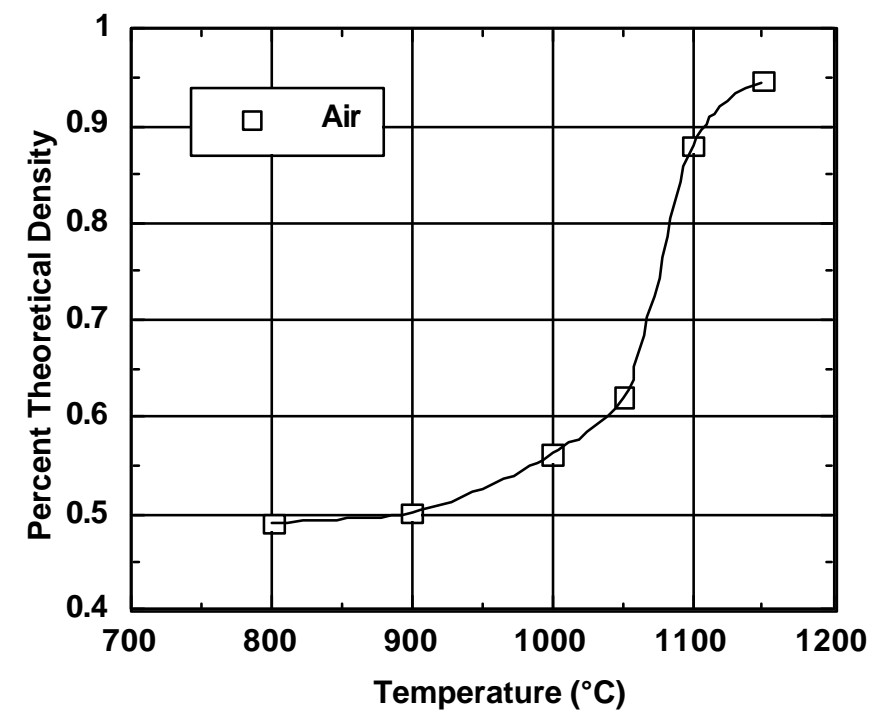

Fig. 3. Density of porous supports as a function of sintering temperature in air, based on theoretical density of $5.0 \mathrm{~g} / \mathrm{cm}^{3}\left(\mathrm{SrCo}_{0.5} \mathrm{FeO}_{\mathrm{x}}\right)$. Ramp rate $5{ }^{\circ} \mathrm{C} / \mathrm{min}$, with $2 \mathrm{hr}$ soak at peak temperature.

XRD has also been conducted on the sintered supports to ensure compatibility with the phase(s) ultimately desired in the final membrane layer. Fig. 5 shows that supports sintered in air are predominantly a layered perovskite structure; whereas supports sintered in $\mathrm{N}_{2}$ consist of a multiphase mixture of a brownmillerite structure, cubic $\mathrm{CoO}$, some layered perovskite, and perhaps also some cubic perovskite. These results are consistent with other reports in the literature. 
Powders for the membrane layer were produced using aerosol pyrolysis from an aqueous nitrate solution with metals in the desired ratio: $\mathrm{Sr}: \mathrm{Co}: \mathrm{Fe}=1: 0.5: 1$. The as-produced powder possessed an average particle diameter of approximately $0.2-0.3 \mu \mathrm{m}$. The composition of the powders was evaluated by AA, and the results are shown in Table 1 . Deviations from the nominal composition are relatively small, though Fe is typically $5-10 \%$ below the nominal level. This may be due to inaccurate knowledge of the hydration state of the Fe nitrate when mixing solutions. Nevertheless, the composition was sufficiently close to nominal for membrane fabrication. The powder produced at $700{ }^{\circ} \mathrm{C}$ consisted primarily of single-phase perovskite $\mathrm{Sr}(\mathrm{Fe}, \mathrm{Co}) \mathrm{O}_{3-\mathrm{x}}$ (by XRD) for both air and $\mathrm{N}_{2}$, with small amounts of secondary phases (Fig. 6).

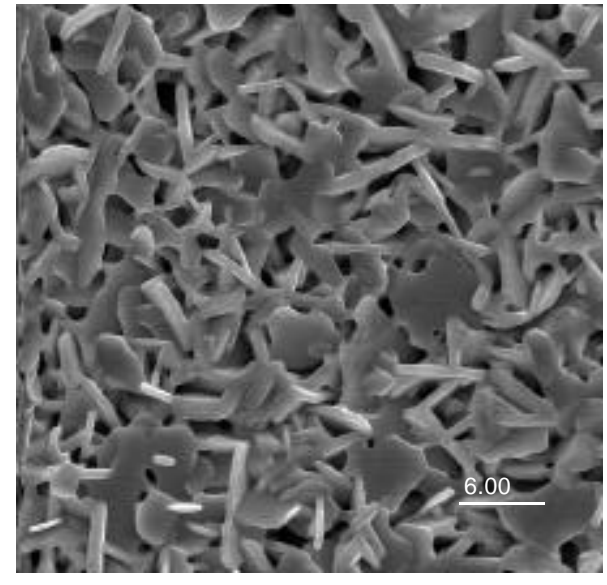

Air at 1050

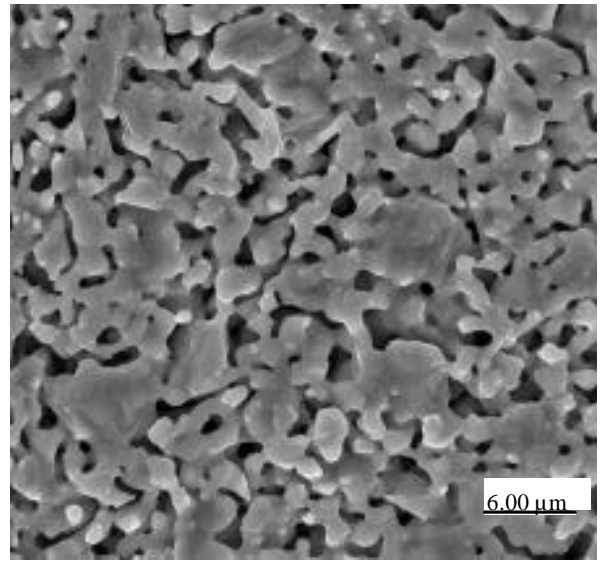

$\mathrm{N}_{2}$ at $1050{ }^{\circ} \mathrm{C}$

Fig. 4. Scanning electron micrographs showing $\mathrm{SrCo}_{0.5} \mathrm{FeO}_{\mathrm{x}}$ supports after sintering at $1050{ }^{\circ} \mathrm{C}$ in air and nitrogen.

\section{Phase Content of $\mathrm{SrCo}_{0.5} \mathrm{FeO}_{\mathrm{X}}$ Supports}

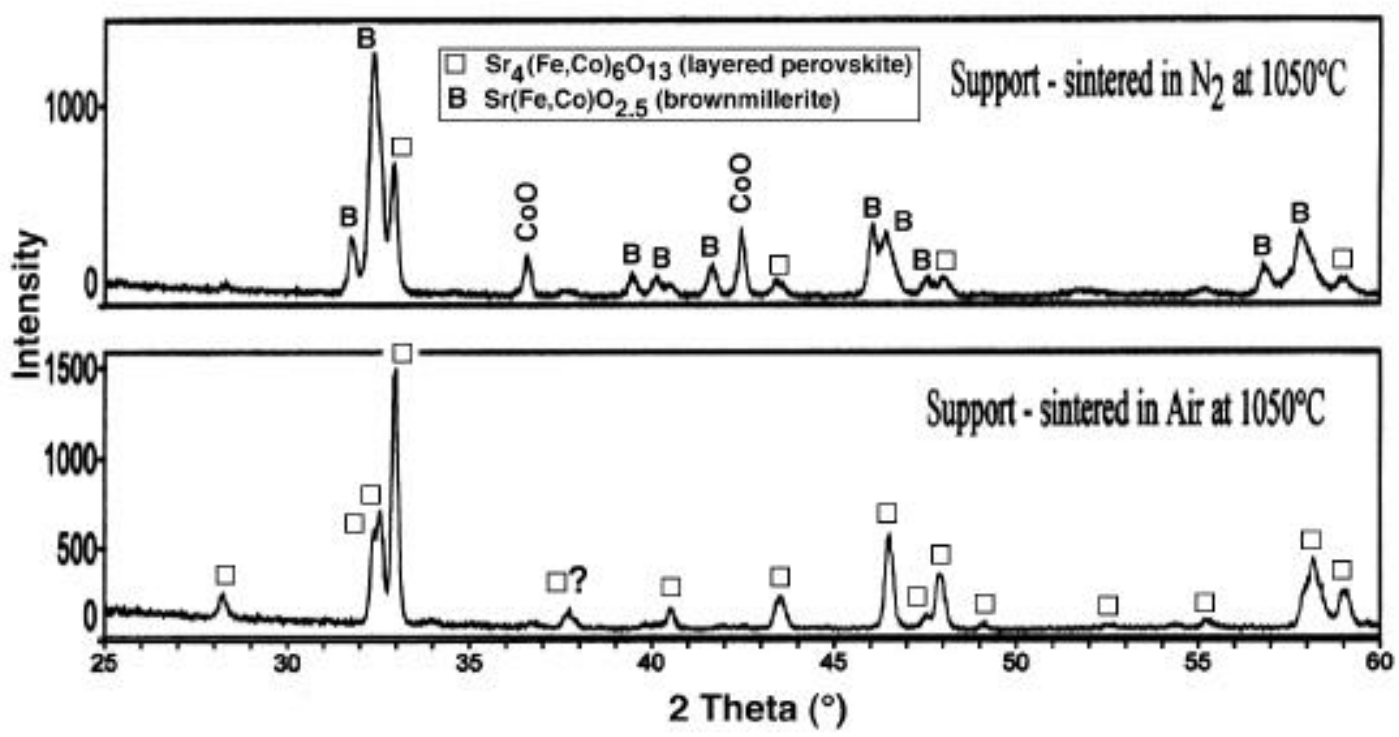

Fig. 5. X-Ray diffraction data for $\mathrm{SrCo}_{0.5} \mathrm{FeO}_{\mathrm{x}}$ supports after sintering at $1050{ }^{\circ} \mathrm{C}$ in air and nitrogen. 
Table 1. Compositions (by atomic absorption) of SCFO powder produced by aerosol pyrolysis with nominal composition (i.e., stoichiometry in precursor solution) of $\mathrm{SrCo}_{0.5} \mathrm{FeO}_{\mathrm{x}}$ (compositions normalized to $\mathrm{Co}_{0.5}$ ).

\begin{tabular}{ccc} 
Furnace Atmosphere & Furnace Temperature $\left({ }^{\circ} \mathrm{C}\right)$ & Composition \\
\hline \hline Air & 700 & $\mathrm{Sr}_{0.96} \mathrm{Co}_{0.50} \mathrm{Fe}_{0.94} \mathrm{O}_{\mathrm{x}}$ \\
$\mathrm{N}_{2}$ & 700 & $\mathrm{Sr}_{1.00} \mathrm{Co}_{0.50} \mathrm{Fe}_{0.89} \mathrm{O}_{\mathrm{x}}$ \\
$\mathrm{N}_{2}$ & 800 & $\mathrm{Sr}_{1.04} \mathrm{Co}_{0.50} \mathrm{Fe}_{0.91} \mathrm{O}_{\mathrm{x}}$
\end{tabular}

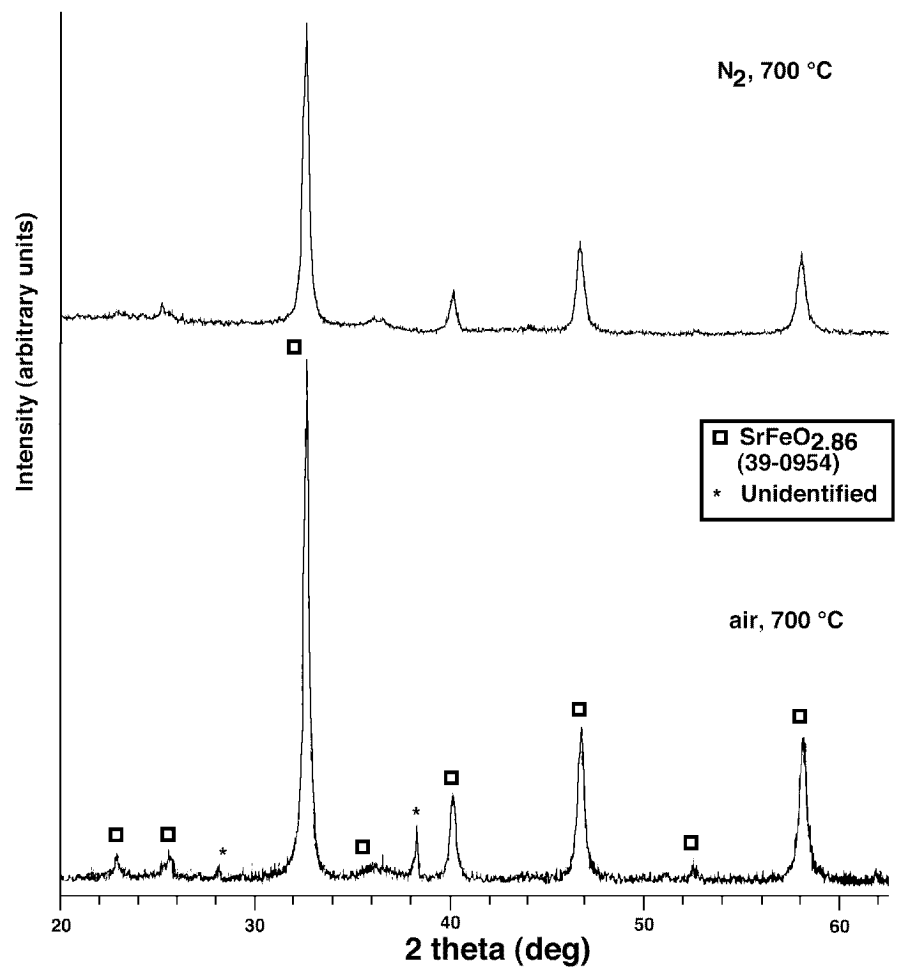

Fig. 6. X-ray diffraction (XRD) patterns of aerosol powder produced in air and $\mathrm{N}_{2}$ from nitrate solution with nominal overall composition $\mathrm{SrCo}_{0.5} \mathrm{FeO}_{\mathrm{x}}$.

Powder was fabricated in both $\mathrm{N}_{2}$ and air since it is known that atmosphere affects the sintering behavior and crystalline evolution. Determination of an optimal combination of support fabrication, powder synthesis and co-sintering of support and film was one of the desired outcomes of the research; thus, all processing was examined in both atmospheres. It was found that adequate crystallinity was present in powder produced at $700{ }^{\circ} \mathrm{C}$, though crystallinity improved at higher temperatures. Based on these experiments, $700{ }^{\circ} \mathrm{C}$ was adopted as the standard production temperature. The crystalline phase content of as-produced powder was very similar for both air and $\mathrm{N}_{2}$ synthesis (Fig. 6).

Several different methods were explored for depositing the aerosol powder as thin and thick films, as described in the Experimental section. The results presented below were obtained by 
the doctor blade method. This approach provided individual particle layers that were typically at least 5-10 $\mu \mathrm{m}$ thick on the porous support. The supported "green" films were then subjected to heat treatments in order to remove the paste solvent or diluent and sinter the films. The thick films deposited by this method had good coverage and were relatively free of cracks and large defects prior to sintering. Furthermore, the film integrity was maintained during sintering. This can be an issue because diffusion between the film and support can compromise the integrity of supported thin films.

Though film integrity was maintained, considerable cracking and/or void generation of the membrane typically accompanied solvent removal and film densification. The gas atmosphere $\left(\mathrm{O}_{2}\right.$ content) during sintering was found to strongly influence the densification, microstructure and crystalline phase evolution of the films (as well as the supports described above). Fig. 7 shows relatively low resolution micrographs which reveal the large-scale cracking seen in thick films sintered in air and $\mathrm{N}_{2}$. The plate-shaped grain structure is again evident for air-sintered samples, and it clear that shrinkage is considerable greater for the $\mathrm{N}_{2}$-sintered films. The greater shrinkage also leads to larger scale cracks and openings in the $\mathrm{N}_{2}$ sintered films. However, the film regions for $\mathrm{N}_{2}$ sintering are essentially completely dense, whereas the air sintered film still appears to have considerable open porosity (Fig. 8). These data reveal that $\mathrm{N}_{2}$ sintering is much preferred for film densification; however, the images also show the inherent challenges in trying to densify a porous film in such a way that in-plane shrinkage does not crack and open up the film. XRD to provide complementary information on the phase evolution in the different gas environments has not yet been completed, but will be part of the continued exploration of sintering behavior in the second project year.
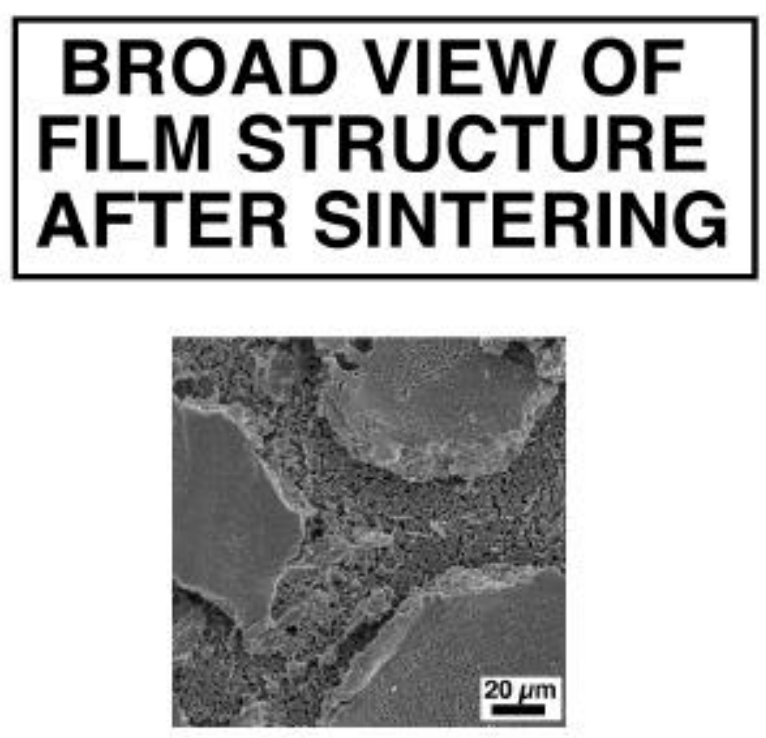

$\mathrm{N}_{2}, 1050^{\circ} \mathrm{C}$

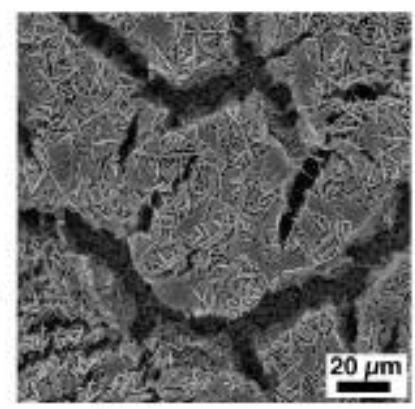

Air $1050^{\circ} \mathrm{C}$

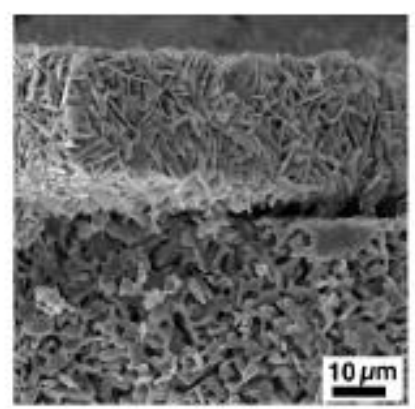

Fig. 7. Scanning electron micrographs showing typical extent of cracking and opening up of membrane films after sintering in $\mathrm{N}_{2}$ and air. 


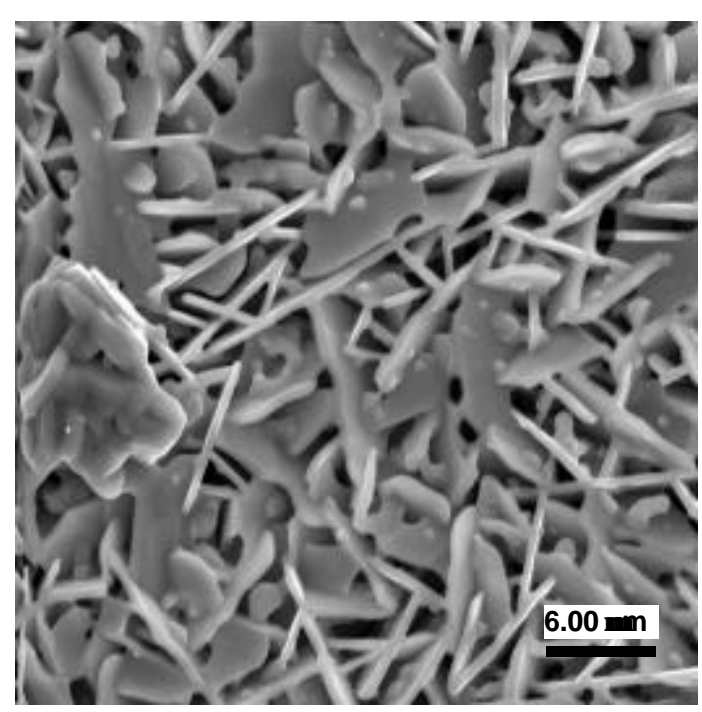

(a)

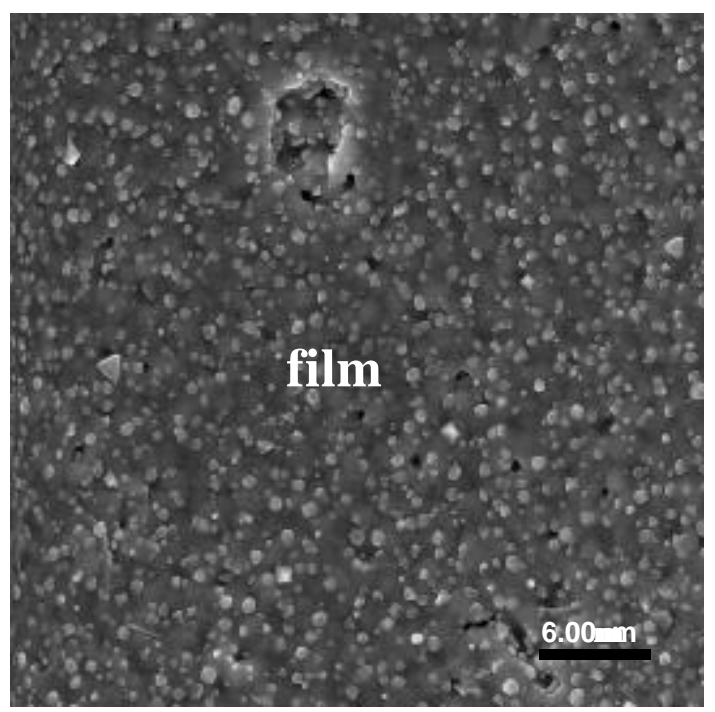

(b)

Fig. 8. SEM of thick $\mathrm{SrCo}_{0.5} \mathrm{FeO}_{\mathrm{x}}$ thick films sintered in air (a) and nitrogen (b) at $1050{ }^{\circ} \mathrm{C}$.

\section{CONCLUSION}

The results obtained thus far on this project have demonstrated the following: $\mathrm{SrCo}_{0.5} \mathrm{FeO}_{\mathrm{x}}$ supports can be produced that provide adequate strength and porosity, thick films can be produced using aerosol-derived powders with good control over elemental composition and ultimate crystalline phase content, and sintering in $\mathrm{N}_{2}$ is promising for densification of the deposited thick membrane layers. However, the associated development of uncovered areas of the support during sintering due to cracking and constrained sintering is a major hurdle that must be overcome to produce viable gas-tight membranes. Several strategies are being pursued to address these problems in ongoing research: reducing the volume fraction of solvent/diluent in the paste, depositing thinner individual layers $(5-10 \mu \mathrm{m})$, and depositing multiple layers with sintering between layers (effectively using subsequent layers to fill flaws developed in the previous sintering cycle). We have only just begun investigating a flaw mending strategy based on chemical vapor deposition (CVD) which could be used to block pin holes and small defects. This strategy, discussed in the project proposal, involves CVD of a metal using controlled flow and counter-diffusion of a metal-organic precursor and $\mathrm{H}_{2}$. A nonreactive metal (e.g. Pt) may be used, or a compatible metal that deposits or may be converted to an oxide (e.g. Sr or Fe oxide).

\section{REFERENCES}

1. B. C. H. Steele, "Oxygen Ion Conductors and their Technological Applications", Mater. Sci. Eng. B13, 79 (1992).

2. T. L. Ward, G. P. Hagen, and C. Udovich, "Assessment of Inorganic Membrane Technology of Petrochemical Applications", in Proceedings of the Third International Conference on Inorganic Membranes, July 10-14, 1994, Worcester Polytechnic Institute, 100 Institute Rd, Worcester, MA 01609.

3. U. Balachandran, J.T. Dusek, R. L. Mieville, R. B. Poeppel, M. S. Kleefisch, S. Pei, T. P. Kobylinski, C. A. Udovich and A.C. Bose, "Dense Ceramic Membranes for Partial Oxidation of Methane to Syngas", Appl. Catal. A 133, 19 (1995). 
4. Y. Teraoka, T. Fukuda, N. Miura, and N. Yamazoe, "Development of Oxygen Semipermeable Membrane Using Mixed Conductive Perovskite-Type Oxides (Part 2) Preparation of Dense Film of Perovskite Type Oxide on Porous Substrate", J. Ceram. Soc. Jpn. Inter. Ed. 97, 523 (1989).

5. Y. Teraoka, H.-M. Zhang, S. Furukawa and N. Yamazoe, "Oxygen Permeation Through Perovskite-Type Oxides", Chem. Lett. 1985, 1743-1746 (1985).

6. Y. Teraoka, T. Nobunaga and N. Yamazoe, "Effect of Cation Substitution on the Oxygen Semipermeability ofPerovskite-type Oxides", Chem. Lett. 1988, 503 (1988).

7. Y. Teraoka, H. M. Zhang, K. Okamoto and N. Yamazoe, "Mixed Ionic-Electronic Conductivity of $\mathrm{La}_{1-\mathrm{x}} \mathrm{Sr}_{\mathrm{x}} \mathrm{Co}_{1-\mathrm{y}} \mathrm{Fe}_{\mathrm{y}} \mathrm{O}_{3-\delta}$ Perovskite-Type Oxides", Mat. Res. Bull. 23, 51 (1988).

8. B. Ma, U. Balachandran, J.-H. Park and C. U. Segre, "Electrical Transport Properties and Defect Structure of $\mathrm{SrFeCo}_{0.5} \mathrm{O}_{\mathrm{x}}$ ", J. Electrochem. Soc. 143 (5), 1736 (1996).

9. A. Gurav, T. Kodas, T. Pluym and Y. Xiong, "Aerosol Processing of Materials", Aerosol Sci. Technol. 19, 411 (1993).

10. T. T. Kodas and M. Hampden-Smith, Aerosol Processing of Materials, Wiley-VCH, New York (1999). 